\title{
Geografía y nación. Claudio Gay y la primera representación cartográfica de Chile ${ }^{1}$ \\ Geography and Nation: Claudio Gay and the first maps of Chile
}

\author{
Rafael Sagredo Baeza*
}

\section{INTRODUCCIÓN}

En el contexto de los estudios destinados al problema de la organización de las repúblicas, la consolidación de los estados y la formación de las naciones luego de la independencia de América, el papel de las exploraciones geográficas y de las representaciones cartográficas de los territorios de los nuevos estados a que ellas dieron lugar, no ha sido motivo de mayor preocupación, desaprovechando así las potencialidades analíticas que éstas ofrecen para la comprensión de estos procesos ${ }^{2}$.

Obras como las de Claudio Gay sobre Chile, Alcide d'Orbigny respecto de Bolivia, Agustín Codazzi sobre Venezuela y la Nueva Granada, o la de Antonio Raimondi en relación al Perú, permiten apreciar la participación determinante

\footnotetext{
* Académico del Instituto de Historia de la Pontificia Universidad Católica de Chile y Conservador de la Sala Medina de la Biblioteca Nacional. (rsagredo@puc.cl).

${ }^{1}$ Este trabajo ha sido preparado en el contexto del proyecto FONDECYT No 1051016.

2 Por ejemplo en la estimulante obra coordinada por Annino y Guerra, (2003), no aparece ningún trabajo que aborde el tema desde la perspectiva que proponemos. La razón de este olvido tal vez se encuentre en que, en general, los historiadores tienden a considerar los mapas como un tipo de evidencia de menor categoría que la palabra escrita. O, quizás, porque sólo los consideran útiles en cuestiones históricas determinadas como lo son los relativos a los descubrimientos o la expansión territorial.
} 
que los naturalistas tuvieron en el reconocimiento de los países que exploraron, pero también en la conformación de nacionalidades, el desarrollo de identidades regionales, la integración de pueblos y sociedades o, esencial, en la identificación de un destino, un futuro común, ahora como estados nacionales.

Considerando que la mayor parte de los naturalistas que exploraron y se ocuparon de estudiar las distintas regiones de América en el siglo XIX siguieron más o menos fielmente el modelo científico practicado por Alexander von Humboldt, no debe extrañar que el resultado de sus investigaciones avalara la existencia de los nuevos estados. Ellos, en su afán por abarcarlo todo y conocer los ambientes, especies y recursos naturales de los territorios bajo la soberanía de las noveles repúblicas objeto de su preocupación, terminaron justificando apasionadamente sus existencias, legitimando científicamente su viabilidad económica y social, pero también identificando sus características culturales. De este modo, si Alexander von Humboldt después de sus investigaciones por el mundo fue capaz de concebir el Cosmos, naturalistas y exploradores como Claudio Gay, Alcide d'Orbigny, Antonio Raimondi o Agustín Codazzi, al describir precisa y exactamente los territorios de Chile, Bolivia, Perú, Venezuela y Nueva Granada contribuyeron a la creación, desde el conocimiento científico, de estas repúblicas sudamericanas que, además, definieron entusiastamente. Demostración de ello son la Historia física y política de Chile de Gay, El Perú de Raimondi, la Descripción geográfica, histórica y estadística de Bolivia de d'Orbigny y las geografías de Codazzi; todas, verdaderos certificados de identidad de las nuevas repúblicas, a la vez que fundamentos científicos e intelectuales de las respectivas naciones.

En estas obras, concebidas originalmente como historias naturales, y que debido a las necesidades de las autoridades republicanas terminaron transformándose también en historias nacionales, las descripciones científicas de los espacios bajo la soberanía del nuevo Estado, y las representaciones cartográficas que ellas permitieron elaborar, constituyen elementos esenciales del proceso de representación, conocimiento y control de los territorios de los noveles estados.

Considerando que no sólo hay que conocer los mapas, sino también comprenderlos, apreciarlos en tanto ofrecen un conocimiento esencial para la reconstrucción del proceso histórico experimentado en América luego de la independencia, abordamos el estudio de la obra cartográfica del naturalista Claudio Gay sobre Chile. Sostenemos que ella se transformó en un aporte sustantivo al conocimiento geográfico de la nueva república, en instrumento fundamental de la administración estatal y en herramienta invaluable de la 
integración territorial de la sociedad que, a lo largo del siglo XIX, se consolidó como Estado y nación. Entre otras razones, por la efectiva representación gráfica que difundió a través de las láminas geográficas de su Atlas de la Historia física y política de Chile 3 .

Nos motiva la concepción de la cartografía como construcción social; en tanto conjunto de imágenes cargadas de intenciones y consecuencias que se deben estudiar en su contexto, pues son producto de los valores de la sociedad.

Tras nuestro planteamiento está la noción de los mapas como textos producidos de forma deliberada, con una dimensión simbólica que los transforma en metáforas de la sociedad; su concepción como retórica a través de la cual se busca persuadir; como instrumentos nunca neutrales o completamente científicos. En fin, la idea de que los mapas hablan e invocan la autoridad, especialmente los oficiales; que apelan a los lectores y pretenden convencer; que se dirigen a un público específico, de un momento concreto, de un contexto identificable que conforma una realidad indispensable de atender para interpretarlos ${ }^{4}$.

Como podrá comprenderse, que hagamos de Gay y su obra el objeto de nuestro estudio, no significa que deba atribuírsele la autoría única del fenómeno que nos interesa mostrar. En realidad, el sabio francés, en tanto agente del Estado, es la figura de un proceso que el gobierno republicano había iniciado con anterioridad. Es el protagonista, en medio de un numeroso elenco, por sus conocimientos, su dimensión internacional, la amplitud de sus trabajos, la tarea de recopilación que llevo adelante; pero, sobre todo, por su calidad de científico y su capacidad de generar un discurso basado en un método aceptado universalmente que, a través de él, el Estado chileno hizo suyo.

\section{Un CIENTíFICO EN CHILE}

Según sus principales biógrafos, el arribo de Claudio Gay al país en los primeros días de diciembre de 1828 fue consecuencia de su contratación como profesor del Colegio de Santiago, cuyas actividades docentes se iniciarían en marzo de 18295 .

\footnotetext{
3 A Claudio Gay se debe también la primera historia compuesta sobre Chile.

${ }^{4}$ Una reflexión sobre estos planteamientos, en Harley, 2005.

5 Stuardo Ortiz 1973, es quien más acabadamente ha investigado acerca de la vida del científico. En su obra póstuma se reproducen numerosos escritos de Gay, o concernientes a su labor en Chile, así como diversos textos relativos a su persona.
} 
Más entusiasmado con sus excursiones que con sus clases, a la vez que revelando los motivos que lo habían traído a Chile, el propio Gay escribía a Alexandre Brongniart el 9 de diciembre de 1829 que a pesar de que "no disponía más que de un día a la semana en provecho de las ciencias" y que, sobre todo al comienzo de su estadía, no le era posible más que "visitar solamente los alrededores de Santiago o realizar un viaje rápido a la orilla del mar o a la cordillera", ya había realizado "una buena serie de observaciones que bastarán para dar a conocer estas comarcas tan poco visitadas por los naturalistas"6.

El interés que Gay mostraba por la historia natural llamó la atención de las autoridades, en las cuales rondaba la idea de estudiar científicamente el país, una antigua aspiración que no había podido materializarse por falta de una persona idónea para acometer la empresa.

En el Chile de la organización republicana, donde todo estaba por hacerse, y en medio de las tribulaciones políticas y la pobreza del erario, hubo gobernantes que tuvieron plena conciencia de la necesidad de conocer cabal y científicamente el territorio y la realidad nacional. Entonces, ni siquiera existían mapas medianamente aceptables; poco se sabía de la situación exacta de las ciudades y puntos geográficos de importancia; nadie había estudiado sistemáticamente las especies naturales; y, menos aún, preocupado de las características geológicas o de precisar adecuadamente las condiciones climáticas de los ambientes en que comenzaba a desenvolverse la nueva república.

En julio de 1830 Gay redactó una presentación dirigida al Vicepresidente de la República a través de la cual ofrecía sus servicios como naturalista. A cambio de sus trabajos, los cuales, declaraba, sólo podrían ser publicados en Europa, solicitó auxilio para continuar sus investigaciones y el auspicio del gobierno para sus trabajos. En pago de sus servicios, Gay no pidió al gobierno ni grandes salarios, ni demasiados favores, "sino sólo su protección cerca de las autoridades provinciales y los gastos indispensables de los viajes que mis investigaciones me obligan a hacer"7.

En septiembre de 1830 se autorizó al Ministro del Interior para suscribir un acuerdo con Gay en virtud del cual quedaría sellado su viaje científico por el territorio. Como justificaciones se esgrimían, tanto la trascendencia de la iniciativa, como las cualidades de Gay para verificarlo con ventaja para el país.

\footnotetext{
${ }^{6}$ Feliz Cruz y Stuardo Ortiz, 1973, p. 2.

${ }^{7}$ El texto a través del cual Gay ofreció sus servicios al gobierno chileno, en (Stuardo Ortiz, 1973, t. II, pp. 87-90).
} 
Según el contrato firmado el 14 de septiembre de 1830, Gay quedó obligado a hacer un viaje científico por todo el territorio de la república, en el término de tres años y medio, con el objeto de investigar la historia natural de Chile, su geografía, geología, estadística y todo aquello que contribuyera a dar a conocer los productos naturales del país, su industria, comercio y administración. Además, al cuarto año, debía presentar un bosquejo de las siguientes obras: una historia natural general de la república que contuviera la descripción de casi todos los animales, vegetales y minerales, acompañados de láminas coloreadas proporcionadas a los objetos que describa; una geografía física y descriptiva de Chile, con observaciones sobre el clima y temperatura de cada provincia, y adornada con cartas geográficas de cada una, y con láminas y planos de las principales ciudades, puertos y ríos; un tratado de geología relativo a Chile; y una estadística general y particular de la república, ordenada por provincias. También se comprometía a formar un gabinete de historia natural con las principales producciones vegetales y minerales del territorio y un catálogo de todas las aguas minerales existentes en el país, con sus respectivos análisis químicos ${ }^{8}$. El científico se comprometió a publicar su obra tres años después de concluida su labor9.

Concluidos los trámites administrativos y los preparativos indispensables para emprender el viaje científico, el naturalista se dispuso a acometer la exploración del territorio nacional, empresa que inició por la provincia de Col-

8 El texto del contrato entre Gay y el gobierno chileno, en Stuardo Ortiz, 1973, t. II, pp. 91-93.

${ }^{9}$ No sobra señalar que las diligencias destinadas a contratar a Claudio Gay se realizaron casi exactamente después de la visita a Chile del naturalista Alcide d'Orbigny. Éste había sido enviado por el Museo de Historia Natural de París para realizar una misión científica que, prolongándose entre 1826 y 1833, lo llevó a explorar Brasil, Argentina, Uruguay, Chile, Bolivia y Perú.

El autor de Viaje a la América meridional, arribó a Valparaíso el 16 de febrero de 1830, puerto del que salió el 8 de abril luego de visitar también Santiago. En la capital del país permaneció sólo ocho días, en los cuales no sólo recorrió sus alrededores y conoció diversas personas, también, realizó una ascensión a los Andes en compañía de Claudio Gay.

Fue al momento de salir de Chile que d'Orbigny recibió, a través del cónsul francés en el puerto, la carta del general Santa Cruz, entonces Presidente de Bolivia, invitándolo a investigar las riquezas naturales del país del altiplano, adelantándole que le conseguiría, como efectivamente ocurrió, todas las facilidades deseables para sus exploraciones y estudios.

En su monumental obra, publicada entre 1835 y 1847 en nueve tomos y 11 volúmenes, d'Orbigny refiere que su corta estadía en Chile no le permitió "generalizar mis observaciones, lo que me obliga a pasar por alto lo que podría decir de Chile", agregando todavía: "por lo demás, no quiero usurpar el derecho que una larga permanencia en la República de Chile da al señor Gay para describirla". 
chagua en diciembre de 1830, y culminó en Atacama en enero de 1842, después de recorrer todas las provincias existentes ${ }^{10}$. Con su última excursión, Gay cumplió su íntimo anhelo de "no dejar ningún punto de Chile sin haberlo realmente visitado", como se lo hizo saber a Ignacio Domeyko en carta fechada el 8 de diciembre de 1841. Al respecto, no debe olvidarse que en esa época el desierto de Atacama era el límite septentrional del país, y que todavía no se iniciaba el esfuerzo destinado a asegurar la soberanía nacional sobre el estrecho de Magallanes y su entorno.

En el cumplimiento de su comisión, desarrolló un patrón de conducta que cumplió rigurosamente durante sus excursiones, y que explica el éxito final de su empresa científica. En cada lugar que visitó o recorrió, procedió a examinar y estudiar las especies naturales, recolectando todas aquellas que le resultaban de interés. Preocupación especial mostró siempre por herborizar y por observar la adaptación de las plantas en las regiones altas de las cordilleras. Fijar con exactitud la situación de los puntos geográficos, auxiliado por los modernos instrumentos adquiridos en Europa, fue también objeto de su atención. Los estudios geológicos y el levantamiento de la respectiva carta geográfica de la zona visitada constituyeron otras de sus ocupaciones permanentes. En los lugares en que existían procedía también a analizar las aguas termales, determinando, entre otras características, si eran sulfurosas o salinas. La recopilación de estadísticas, de documentación y de todo tipo de noticias de los parajes y poblados recorridos, fueron también actividades características suyas. Por último, sus observaciones climáticas y sus mediciones meteorológicas, así como las destinadas a determinar el magnetismo terrestre, fueron otra constante de su acción.

Aun en medio de las limitaciones presupuestarias, las alteraciones políticas experimentadas por el país o la Guerra contra la Confederación Perú-Boliviana, Gay, paciente, sistemática y casi anónimamente, durante aproximadamente una década, llevó a cabo su comisión, sentando las bases del desarrollo científico del país y recopilando antecedentes que más tarde serían los fundamentos de la nacionalidad chilena. Una tarea que a pesar de carecer de sucesos espectaculares o llamativos, tuvo importancia fundamental en el desenvolvimiento de la nación. Concluida, ahora sólo quedaba el trabajo, no menor, de dar a conocer el fruto de sus investigaciones a través de la respectiva publicación, la cual, como sabemos, incluyó el primer conjunto de mapas de la república de Chile.

10 Barros Arana, 1911, pp. 239-457 y Stuardo Ortiz, 1973, ofrecen abundante información para reconstruir las exploraciones de Claudio Gay por Chile. 


\section{LA CARTOGRAFÍA NACIONAL}

Entre los estímulos que el gobierno tuvo para contratar a Claudio Gay en 1830, determinante fue el relacionado con la posibilidad de contar con una cartografía fiable de Chile, entonces inexistente. Como en muchos otros campos, si bien durante la etapa de la organización de la república se había advertido la necesidad de contar con mapas del territorio, e incluso emprendido iniciativas destinadas a la elaboración de los mismos, lo cierto es que sólo después de 1830 estos planes se materializaron.

Ejemplo de lo afirmado es el decreto de 26 de junio de 1823 que, fundado en "la necesidad de reunir toda clase de datos estadísticos que dirijan al gobierno en las providencias que debe tomar para promover la prosperidad nacional", determinó la realización de "un viaje científico por todo el territorio del Estado" destinado examinar la geología del país, sus minerales y demás materias propias de la historia natural, para lo cual se comisionó a Juan Dauxion Lavaysse. Muy pocos meses después, el 20 de diciembre del mismo año, y como complemento del viaje científico, el mismo gobierno mandaba levantar una carta geográfica del país.

La necesidad de cartografía era fruto de la "diaria experiencia del gobierno" relacionada "con los embarazos que se presentan para dirigir la administración civil y militar y dar un impulso activo a la industria, y al buen orden y economía interior de los pueblos, sin que exista un buen mapa de su territorio". Pero también de la urgencia de cumplir con el mandato del Congreso Constituyente de promulgar una división político administrativa "luego de que se hayan procurado los datos necesarios para verificarla cómoda y provechosamente". Fundado en estos antecedentes, el Director Supremo decretó que "inmediatamente se dará principio a la formación de un mapa corográfico de Chile", confiando la empresa a Alberto D’Albe y a Carlos Ambrosio Lozierll.

Frustradas las iniciativas mencionadas, esencialmente por la incapacidad de los comisionados, sólo a comienzos de la década de 1830 volvió a presentarse la oportunidad de materializarla. Ahora, gracias a la presencia de una persona idónea, Claudio Gay, y un gobierno capaz de sustentarla, el establecido luego de las luchas del año 1829 que llevaron al poder a los conservadores encabezados por Diego Portales.

11 Todos los detalles de estas iniciativas, así como las características de sus protagonistas, en Barros Arana, 1911, pp. 239-457. 
En su plan de trabajo presentado en julio de 1830, el naturalista ofreció levantar "planos de las principales ciudades y ríos y de todas las haciendas que pueda visitar", oferta que en el contrato que firmó con el gobierno en septiembre siguiente se transformó en la obligación de levantar "cartas geográficas de cada una de las provincias y de vistas y planos de las principales ciudades, puertos y ríos" 12 .

Hasta entonces, la única cartografía geográfica e hidráulica existente era la preparada por la Expedición Malaspina en los años de 1790, principalmente costera, con numerosas inexactitudes y muy pocos puntos determinados astronómicamente.

Por eso es que la preparación de un mapa de Chile, que Gay se comprometió a publicar "en grande escala", junto con un atlas con "el mapa de cada una de las provincias", fue una de las tareas que inició desde el momento mismo de su llegada cuando, gracias a sus excursiones por el espacio adyacente a Santiago y estudios en diferentes fuentes, delineó "el plano de la ciudad y cartas geográficas de Chile propiamente dicho", como "del país habitado por los araucanos".

En cada uno de sus informes sobre sus excursiones el naturalista jamás olvidó mencionar que acopiaba todos los datos necesarios para levantar la carta de la respectiva provincia o región explorada. Como afirmó en abril de 1836, "provisto de un círculo de reflexión, de un anteojo astronómico de [Robert] Cauchoix y de tres buenos cronómetros, he podido determinar la latitud y longitud de los principales puntos que he coordinado después por triangulaciones magnéticas". Sería precisamente este método el que le permitió elaborar un mapa más preciso de Valdivia, "que difiere considerablemente de todos los que se han publicado hasta el presente, y espero que permitirá conocer bien esta parte austral de la América, los numerosos lagos que ella encierra, los ríos que nacen y el número exacto de volcanes que existen ${ }^{13}$.

Especial preocupación tuvo por representar los espacios interiores del país, los alejados del litoral del océano Pacífico. Si como afirmó "Chile no posee más cartas geográficas que las de la costa", siendo las del interior "muy imperfectas y la más de las veces formadas sobre datos absolutamente falsos", se comprenderá su interés por levantar una carta geográfica que comprendiera el

12 Stuardo Ortiz, 1973, II, pp. 89 y 91.

13 Véase el texto de su carta sobre sus viajes por el sur de Chile al miembro del Instituto de Francia, Edmond-Francois Jomard, fechada el 25 de abril, en Feliz Cruz y Stuardo Ortiz, 1962, pp. 15-19. 
Chile central ${ }^{14}$. El inmediatamente adyacente a los Andes, aquel en el cual nacían y corrían los ríos, se levantaban los volcanes y se ubicaban los lagos, entre otros muchos elementos naturales imprescindibles de localizar para adecuado conocimiento geográfico del territorio chileno' ${ }^{15}$.

Comprendiendo el valor de sus representaciones, más de una vez explicó que durante sus excursiones se propuso averiguar la posición relativa de los parajes que le eran conocidos o que nombraban sus guías; determinar la posición de los puntos más señalados; establecer los límites de las provincias; dar a conocer el origen, dirección y extensión de los ríos, entre otros objetivos destinados a perfeccionar los mapas del país. Una tarea que definió como un "trabajo de gran utilidad" para las operaciones administrativas del gobierno ${ }^{16}$.

En el informe presentado luego de su viaje a Valdivia y Chiloé, Gay escribió que entre sus trabajos, "el que considero de una utilidad superior es el relativo a la geografía de la república" 17 . Entre otras razones, porque "desde mis primeras observaciones a este respecto he visto cuán falsas y casi indignas de la crítica han sido las cartas de Chile publicadas hasta la fecha" 18 .

Errores groseros, vacíos e inexactitudes, especialmente de la parte interior del territorio y en los pormenores de las representaciones, eran los más comunes. Así, por ejemplo, y para demostrar su evaluación, Gay relata que "en las cartas más recientes, y hasta en las publicadas en 1836, en la provincia de Valdivia la ciudad de Osorno, tan conocida, se halla constantemente colocada sobre un inmenso lago que jamás ha existido, a menos que se haya querido indicar el Llanquihue, casi enteramente desconocido antes de mi visita y situado a más de veinte leguas de esta población".

14 "Viaje científico. Segundo informe sobre sus exploraciones en la provincia de Colchagua". En Stuardo Ortiz, 1973, II, p. 103.

15 Lo dicho, sin embargo, no implica que Gay, que reconoció el valor de las cartas marítimas levantadas por los españoles, especialmente los miembros de la Expedición Malaspina, dejara de advertir los errores de una cartografía preparada apresuradamente. Así por ejemplo, rectificó la posición de Topocalma y de la desembocadura del río Rapel. Véase su ya citado informe sobre su segunda excursión por Colchagua.

16 Véanse los informes sobre sus viajes a las provincias de Valdivia y Chiloé de julio de 1836 y de Coquimbo de febrero de 1831. En Stuardo Ortiz, 1973, II, pp. 211 y 218.

17 "Viaje científico. Estudios realizados en las provincias de Valdivia y Chiloé", Santiago, 4 de julio de 1836. Stuardo Ortiz, 1973, II, pp. 210-212.

18 Sobre este punto, véanse el informe sobre su segundo viaje científico a Colchagua de abril de 1831, o la reseña acerca de sus investigaciones en Chile presentada a la Academia de Ciencias de París en marzo de 1833; ambos en Stuardo Ortiz, 1973, t. II, pp. 103 y 162. 
El 29 de enero de 1841 Claudio Gay publicó en el diario oficial El Araucano el Prospecto de su Historia física y política de Chile. En su propuesta, el naturalista explicaba que editaría su obra sobre Chile dividida en varias secciones, a saber: la flora, la fauna, la minería y geología, la física terrestre y meteorológica, la estadística, la geografía, la historia y las costumbres y usos de los araucanos. Pero el plan no se limitaba sólo a la identificación y descripción de las especies y objetos recolectados y a la elaboración de los estudios realizados según su idea original. El sabio francés tuvo clara noción de la necesidad de acompañar sus textos de "una gran cantidad de láminas iluminadas", no sólo de los animales, plantas y restos que el mundo natural le proporcionaría; también, "con láminas de vistas, vestuarios y planos de las principales ciudades", es decir, con dibujos que ilustrarían la sociedad y sus habitantes.

Para justificar la inclusión en su Historia de los que llama mapas, planos y diseños, explica que una obra como la suya "no puede carecer de estampas, indispensablemente necesarias para que se entienda la explicación de ciertos fenómenos y para facilitar el estudio de todo cuanto concierne a la geografía y a la historia natural". La preocupación del científico por dejar un registro gráfico de sus estudios estuvo presente desde el inicio de sus actividades, y en muchos de los informes que elaboró para el gobierno aludió a los diseños que iba ejecutando a medida que avanzaba en sus investigaciones, dando cuenta también de la realización de planos y cartas geográficas.

Este afán por dejar un bosquejo gráfico de sus investigaciones había dado lugar, afirmó en su Prospecto, a un "cúmulo inmenso de diseños que pasaban ya de 3.000". Al proponer su obra el naturalista creía que el conjunto de dibujos, "perfectamente grabados e iluminados", llegarían a formar tres o cuatro tomos, además de otro consagrado exclusivamente a la geografía. Ofreció entonces, junto al mapa general de la república, "uno especial de cada provincia", además de un mapa de geografía física en el que aparecerían "más de 5.000 alturas de cerros y llanos tomados en todo el territorio; mapas geológicos, botánicos y zoológicos; y una serie de planos de ciudades y puertos con algunas vistas o paisajes de Chile y un pequeño número de estampas relativas a las costumbres araucanas".

Sin duda que al momento de idear su obra, no pensaba en el cúmulo de obstáculos que la publicación debería enfrentar, las cuales, obviamente, le impidieron llevar adelante sus planes originales en lo relativo a las láminas ${ }^{19}$.

19 Para las alternativas de la publicación de la obra de Gay y el contenido de su Atlas, Sagredo, 2004. 
Hacia 1836 Gay ya tenía avanzados algunos levantamientos cartográficos, según se deduce de las noticias que entrega en las crónicas sobre sus excursiones por las provincias; incluso, tiene prácticamente acabado un borrador del mapa de Chile. Lo suficiente como para entregar al Ministerio de Instrucción Pública "una carta que desde todo punto de vista debe merecer toda su confianza", como le hace saber a Manuel Montt en 1843; asegurándole que la misma "es bastante exacta y más que suficiente para cualquier operación administrativa ${ }^{20}$.

Aunque por sus características todas las láminas del Atlas implicaron un trabajo sistemático y prolijo, sin duda que fueron las cartas geográficas las que mayores dificultades y apuros provocaron a Gay. Para su elaboración, en el curso de sus viajes por el territorio chileno el sabio había reunido toda clase de noticias apropiadas para la preparación de mapas. Había llegado a determinar muy aproximadamente la posición astronómica de las localidades, recorrido el curso de muchos ríos, internado en las cordilleras, escalado cumbres muy elevadas y fijado, del mejor modo posible, la altura de muchas montañas. De este modo, al poner fin a sus excursiones, poseía los mejores y más abundantes datos para preparar una verdadera geografía de Chile. Además, en Europa se hizo de las cartas hidrográficas del litoral austral de América levantadas por los españoles e ingleses. Con todo este material, y tomando como cierta la información de las costas que ofrecían los anglosajones, trazó la topografía del interior del país y delineó el litoral de América meridional.

La necesidad del gobierno por adquirir una cartografía adecuada condicionó la obra de Gay. En julio de 1846, y siempre informando al ministro Montt, le escribe que "estoy siempre muy empeñado en la redacción de mi obra, que es un trabajo bastante arduo", pero que también se ocupa de las láminas y cartas. En marzo de 1847 escribe: "entre los dibujos se hallará el mapa de la provincia de Valdivia que he hecho grabar sobre una pequeña escala por la comodidad de la encuadernación". Anunciando que "de aquí en adelante me dedicaré con más preferencia a esta parte de mis trabajos", informa que se ocupará en "confeccionar las cartas de una utilidad más inmediata para las necesidades urgentes de la administración"21.

20 Véase su correspondencia a Manuel Montt fechada el 20 de enero y el 15 de mayo de 1843, en Feliú Cruz y Stuardo Ortiz, 1962, pp. 48 y 52. Finalmente, en septiembre de 1841, en nota a Montt fechada el 11, da por acabada la carta de Chile, el que llama "mi gran mapa".

${ }^{21}$ El apremio de contar con una cartografía, tanto como la tardanza y advertencias de Gay, sumada al arribo de Amado Pissis, a Chile en la década de 1840, llevaron al gobierno a encargarle al experimentado geógrafo francés la preparación de una cartografía levantada sobre la base de observaciones astronómicas. Muestra de las motivaciones estatales, en el contrato 
Atento a las observaciones que se hacían a su obra, y admitiendo que a pesar de la seriedad con que fue ejecutada contenía errores y omisiones, y que sus cartas geográficas probablemente en ocasiones ofrecían posiciones no completamente exactas, evocaba, excusándose, que cuando había iniciado sus trabajos "no había casi nada hecho", y que le fue preciso crearlo todo, a pesar de lo cual había empleado sólo ocho años en reunir sus materiales.

El naturalista es precavido al ponderar el valor de sus mapas. En carta al presidente Montt de 15 septiembre de 1856 le hace saber que cuando, durante sus viajes por Chile, emprendió su elaboración, lo hizo con todo el cuidado de que era capaz, pero que persuadido de que las cartas geográficas demandaban un tiempo extremadamente largo, lo cual perjudicaba sus investigaciones, había optado por recoger los datos por medio de la brújula, observando de distancia en distancia algunas latitudes para sus coordenadas. De tal forma que sus cartas ofrecían la posición de las ciudades, aldeas, ríos y demás fenómenos geográficos, "desde un punto de vista relativo".

Justificaba su método afirmando "este medio era, en esa época, el único que yo tuve que seguir, pues que por más que mis mapas hubieran sido de la mayor exactitud, no habría impedido al gobierno hacerlos recomenzar cuando las necesidades administrativas lo hubieran exigido". Agregando todavía que trabajos como los mencionados son siempre perfeccionables, y que tocaría a los geógrafos captar una idea más exacta de cada provincia, aunque debieran, no obstante, "agradecerme de haberles allanado poderosamente su tarea".

A pesar de las exigencias del gobierno por contar con la cartografía del espacio efectivamente ocupado por el nuevo Estado, Gay se dio tiempo para llamar la atención sobre el contenido que debía incluir su cartografía. Advirtiendo que sus trabajos "no comprenden más que a Chile propiamente dicho, es decir, desde el desierto de Atacama hasta el extremo sur de la isla de Chiloé", agrega que "sin embargo sería conveniente y aun político, que yo hiciera entrar en mi obra toda esta parte del territorio que se extiende desde el gran archipiélago de las Guaitecas hasta el cabo de Hornos, límite extremo de esta república según todas las constituciones publicadas hasta hoy"22.

\footnotetext{
firmado en 1848 se estableció que "el señor Pissis dedicará una particular atención a la cordillera de los Andes, que examinará del modo más prolijo que le sea posible, a fin de señalar con precisión el filo o línea culminante que separa las vertientes que van a las provincias argentinas de las que se dirigen al territorio chileno, y la situación geográfica de los diversos boquetes que permiten el paso por dicha cordillera a las varias provincias de la república".

22 Carta a Manuel Montt fechada en París el 20 de enero de 1843. Feliú Cruz y Stuardo Ortiz, 1962, pp. 45-46.
} 
La visión del científico fue apreciada por el Estado chileno pues, en abril de 1846, y en una carta que dirigió al ministro Montt, Gay comunicaba que "no pierdo ocasión para conseguir nuevas noticias, para que mis trabajos sobre el Estrecho de Magallanes, que de orden suprema debo añadir a mi obra, no se resientan por la ignorancia del terreno".

De este modo, y con indicaciones como la señalada, el naturalista fue delineando, a través de la cartografía sobre su territorio, la república y la nación chilena.

\section{Chile en el Atlas de Gay}

Respecto de los quince mapas incluidos en el Atlas de la historia física y política que representan Chile, las diferentes provincias del país y algunos de sus principales hitos geográficos, es posible sostener que su sola existencia, además de facilitar la historia de la cartografía nacional y enseñar acerca de la conformación política y administrativa de la joven república, muestra la trascendencia que el Estado de la época le asignó a la información geográfica y el valor que Gay le atribuyó para la comprensión de su trabajo.

No puede existir otra explicación para que incluyera dichas cartas, y que en ellas se ocupara de algunos accidentes específicos, como el estrecho de Magallanes, las islas de Juan Fernández o el archipiélago de los Chonos, todas unidades geográficas de gran importancia para la época como se deduce de su presencia en el Atlas. Más todavía, la inclusión, como imagen inicial, de una lámina gigante que debe desplegarse para ser observada, que Gay nombra "Mapa para la inteligencia de la Historia Física y Política de Chile", y en la cual se representa por primera vez todo el país, muestra el afán del naturalista por ofrecer una visión completa del Chile de entonces, en este caso, a través de su presentación in extenso ${ }^{23}$.

La importancia de este mapa se puede apreciar desde numerosas perspectivas. En primer término, por su valor en tanto representación geográfica del territorio chileno en una época en que las mismas son prácticamente inexistentes y poco confiables. Precisamente porque Gay quería hacer saber de la seguridad que su mapa podía ofrecer, es que coloca como nota en el mismo que éste había sido preparado sobre la base de cartas españolas e inglesas "levantadas en estos últimos años".

${ }^{23}$ Confeccionada a escala 1:2.000.000 aproximadamente, en ella se utilizó una proyección Mercator, con graduación en latitud y longitud cada un grado. 
Más trascendente resulta que en el mapa se ofrezca la visión existente en el Chile del siglo XIX sobre los espacios que conformaban su territorialidad. En efecto, en la carta sólo está representada la superficie, entre los Andes y el Pacífico, comprendida entre el desierto de Atacama y la isla de Chiloé, aunque, cierto, con el agregado del recuadro que muestra el estrecho de Magallanes y sus espacios adyacentes. Es decir, un Chile ajeno, como lo era en realidad, a los inhóspitos desiertos de sus extremos y totalmente circunscrito al breve espacio que la cordillera de los Andes deja antes de alcanzar el mar; aunque, como ya veremos, con la aspiración de ejercer soberanía efectiva en la Patagonia occidental hasta el estrecho de Magallanes.

Es la materialización cartográfica de una realidad natural; Chile representado como efectivamente era. Un espacio de gran desarrollo longitudinal que el científico había logrado captar gracias a sus excursiones por el país. Un territorio que pese a su gran longitud en sentido norte sur estaba destinado a integrarse y constituirse en uno solo gracias a la acción de un Estado al que Gay, a través de su mapa, dotaba del instrumento preciso para consolidar y extender su soberanía y, de paso, contribuir a la formación de la nación.

En lo relacionado con la integración nacional, el mapa ilustra los caminos coloniales o "camino real" como se nombran, instrumentos esenciales para la vinculación entre las regiones del país. También ofrece los caminos que en la época permitían "pasar las cordilleras", tanto en dirección a la "República de la Plata", como en el interior del país; sin duda una inclusión fundamental en orden a dar a conocer las vías de comunicación y facilitar el tráfico, tanto de productos y bienes, como de personas. Por último, la carta muestra también el itinerario del naturalista. Manifestación fehaciente de que su trabajo era fruto de la exploración, de la investigación en terreno y, por tanto, garantía de seriedad y acuciosidad científica. La comparación entre el camino real y los derroteros seguidos por el estudioso reflejan que Gay no se limitó a recorrer aquellos lugares y regiones más accesibles, sino que fue más allá en su afán por reconocer y describir a la naciente república.

Por último, el mapa de Chile incluye también un recuadro del litoral de la sección meridional de América del Sur en el cual se identifican los principales puntos y accidentes geográficos de las costas, sin prácticamente ninguna referencia al interior. Destinado a ilustrar de un modo general sobre la región, para su elaboración Gay se sirvió de la cartografía colonial española pues es una reproducción de la "Carta esférica de las costas de la América meridional" levantada por la Expedición Malaspina ${ }^{24}$.

${ }^{24}$ Sobre la expedición ilustrada, Sagredo Baeza y González Leiva, 2004. 
Considerando la falta de noticias y datos sobre esas latitudes, en la representación, como en sus cartas específicas de la región, el naturalista se limitó a delinear los espacios continentales e identificar los fenómenos naturales costeros que la información existente en la cartografía española e inglesa le proporcionó. Esto explica que además de identificar los archipiélagos, islas, canales, cabos y bahías situados en el litoral, solo se contente con nombres muy generales para los territorios interiores, como Patagonia oriental y occidental; o, sencillamente, que nombre como "tierra desconocida" al área entre las dos "patagonias" que se extiende al sur del paralelo 47 y hasta el 52 aproximadamente ${ }^{25}$.

Como hemos advertido, la representación cartográfica del extremo sur de Chile y la inclusión de los archipiélagos australes, estrecho de Magallanes incluido, obedeció a una decisión política más que científica, pues el naturalista no sólo jamás alcanzó hasta esas latitudes, sino que además eran espacios desconocidos, no integrados al territorio chileno o a cualquier otro. Su inclusión en sus mapas debe considerarse una forma de reafirmar las reivindicaciones chilenas sobre aquellas regiones, las cuales, en la década de 1840, ya se habían materializado en actos de soberanía 26 .

De este modo, los mapas de América meridional de Gay no sólo ilustraban sobre una región remota y desconocida desde el punto de vista geográfico, además de ajena a toda manifestación política o administrativa de gobierno alguno; en realidad, la transformaban en chilena por el sólo acto de representarla en la primera cartografía nacional.

En términos de la noción geográfica de Chile, interesante resulta constatar que los mapas de las provincias de Cauquenes, Talca, Colchagua, Santiago y Valparaíso aparecen, en especial las tres primeras, en representaciones con una disposición este-oeste y no norte-sur. En el Chile de entonces, en proceso organización y consolidación nacional, Gay percibe que en algunas zonas aún prevalece el ordenamiento espacial colonial en función de ejes horizontales o transversales marcados por el curso de los ríos que van de la cordillera al mar. Éstos determinan y organizan un espacio regional que gracias a los trabajos

${ }^{25}$ La mayor parte de los topónimos en idioma inglés, explican claramente el origen de la cartografía consultada por Gay.

${ }^{26}$ En 1843 se había tomado posesión efectiva del territorio adyacente al Estrecho de Magallanes a través de la fundación de una población llamada Fuerte Bulnes. Para el gobierno y opinión de la época, el control del Estrecho era de importancia fundamental en razón de las posibilidades de contacto con Europa que él abría, y el consiguiente comercio que la mayor cercanía traería. 
del científico comenzará a transformarse dando paso al proceso de unificación territorial del Estado y la nación que, sabemos, desestructurara los ejes regionales horizontales en favor de un solo eje vertical, norte-sur, una de cuyas expresiones intelectuales es el mapa de Gay y, más tarde, el ferrocarril longitudinal. Sin duda una manifestación geográfica de la consolidación y del dominio del Estado centralizado sobre el territorio y, por tanto, también, de construcción de la nación.

Otra expresión del proceso descrito es la inclusión en el Atlas de nueve mapas con la representación de las unidades político administrativas delineadas por la nueva república ${ }^{27}$. Hasta ese momento nunca antes se habían representados las provincias que sucesivamente se habían ido creando desde 1812 en adelante, hasta completar 13 en 1853. Ordenadas de sur a norte, Gay ofrece los mapas de Chiloé, Valdivia, Concepción, Cauquenes, Talca y Colchagua, Santiago y Valparaíso, Aconcagua, Coquimbo y Atacama.

Si bien las representaciones cartográficas no corresponden exactamente a las divisiones político administrativas existentes, pues no aparecen las provincias de Maule, Ñuble y Magallanes y jamás existió la que Gay nombra Cauquenes, lo cierto es que de todas formas la obra del naturalista representa un hito al mostrar el territorio de Chile ordenado por el Estado en uso de sus facultades soberanas ${ }^{28}$. En estas cartas están los principales hitos de cada división político administrativa, como lo son los límites provinciales y departamentales, las poblaciones, las capitales y las vías de comunicación. Pero también los fenómenos geográficos más señalados contenidos en cada una de ellas, como ríos, cerros, lagos, islas y, en general, las formas del litoral.

En virtud de todo lo anterior, y más importante todavía, en cada uno de sus mapas Gay ofreció información geográfica que va más allá del litoral oceánico y los espacios inmediatos a él. Gracias a sus excursiones pudo identificar, nombrar y situar las poblaciones y formas y unidades naturales existentes al interior del territorio, contribuyendo no sólo a delinear el espacio nacional, también a configurarlo al darle un contenido preciso, reconocible e identificable.

Considerando que nunca se había levantado una carta geográfica del interior de Chile, el conjunto de representaciones cartográficas del naturalista le dio profundidad espacial al territorio nacional al expandir su mirada más allá

\footnotetext{
${ }^{27}$ Las cartas particulares están levantadas a escalas que varían desde 1:800.000 y 1:500.000.

28 Una explicación posible para las inexactitudes o vacíos de la cartografía provincial del Atlas puede encontrarse en el hecho de que Gay sólo permaneció en Chile hasta 1842, cuando todavía no se creaban las provincias de Atacama, Nuble y Magallanes y, obviamente, no recibió la información precisa.
} 
de las formas de las costas del Pacífico. Por el sólo hecho de situar y representar la realidad cultural y natural de los espacios que se extendían hasta los Andes, lo dilató en sentido este-oeste, contribuyendo así a su identificación como unidad geográfica, pero también política.

Con su acción, y aplicando el conocimiento que le dieron sus viajes por el país, Gay siguió el modelo geográfico entonces imperante. Aquel señalado por Alexander von Humboldt al identificar y caracterizar los espacios naturales a partir de los elementos que los distinguían que, en este caso, resultó en la creación de Chile, tanto en su condición de unidad natural como política. No por nada escribió que si el globo se dividía en regiones en razón de la apreciación de los géneros y especies peculiares a cada una de ellas, "ningún país más digno de ser elevado al título de región que la república de Chile. Perfectamente limitado por barreras infranqueables"29.

Claudio Gay pudo delinear cartográficamente Chile pues lo había estudiado exhaustivamente, identificado como una realidad geográfica, y caracterizado en sus rasgos más sobresalientes desde el punto de vista ambiental. En la sección destinada a la historia natural de su Historia física y política abordó el estudio de la flora y fauna del país bajo los rótulos de botánica y zoología, sosteniendo que Chile sobresalía porque tenía un carácter particular derivado de las barreras naturales que cerraban todo su contorno, transformándolo en una "región enteramente natural"30. En lo que desde Pedro de Valdivia en adelante constituye un verdadero estereotipo o lugar común, el naturalista francés también señaló el clima y las condiciones ambientales generales como una cualidad propia del territorio nacional. De este modo, calificativos como el de "hermoso", "delicioso" y "ameno" que aplicó a Chile no deben sorprender si se considera que su objeto de estudio constituía un espacio geográfico de una "prodigiosa feracidad", "privilegiado por la naturaleza", que él, revestido con el prestigio del científico, avalaba y daba a conocer. En definitiva, el territorio

29 "Fragmentos de geografía botánica de Chile", presumiblemente de 1854, Stuardo Ortiz, 1973, II, pp. 318-329.

30 El chileno no fue el único caso en que se atribuyó un papel a la realidad natural en la delimitación del espacio nacional. Así por lo menos se aprecia en la geografía de Venezuela de Agustín Codazzi quién, bajo el rotulo de "Fronteras naturales", escribió que "las fronteras que la naturaleza parece haber destinado a Venezuela, no son las que le ha trazado la política". En sus palabras, "las crestas de estas montañas parecen indicadas por la naturaleza para partir límites entre Venezuela y la Nueva Granada; así como el curso total del Esequibo formaría por la parte opuesta una división muy natural con la Guayana Inglesa. Cerraríase este espacio del lado S. por los montes que separando la hoya del Amazonas de la del Orinoco, y corriendo hasta unirse con el páramo de Aponte, parecen llamadas a fijar las fronteras de Venezuela y del Brasil. Codazzi, 1841, pp. 1 y 2. 
que quedó fijado en el mapa de Chile que el naturalista levantó era la expresión material de "la copia feliz del Edén", como la quinta estrofa de la canción nacional lo nombraba metafóricamente ${ }^{31}$.

Identificado como unidad física y política, Chile fue divido en regiones geográficas. A partir de las características del paisaje y de la vegetación el sabio diferenció tres zonas: Norte, Centro y Sur; dando origen a las regiones que, desde entonces, y con leves variantes, se han identificado para dividir geográficamente el país, y a partir de las cuales se han trazado, en más de una ocasión, las divisiones político administrativas.

La del sur se distinguía por sus vastos bosques de proteáceas, mirtáceas y cunoniáceas y una cubierta vegetal muy espesa que se extendían desde el mar hasta la cordillera, comprendiendo las provincias de Chiloé, Valdivia y parte importante de la de Concepción; la del norte, por el contrario, encerraba vastos desiertos de arenas y se caracterizaba por su gran aridez y sequedad y por sus familias de cactáceas, solanáceas y leguminosas; la del centro, que corresponde a la transición entre las nombradas, "se hallaba limitada en sus extremos por varios árboles propios de esta república, como son los que se conocen vulgarmente con los nombres de "peumo", "patagua", "quillay" 32.

Luego de esta primera división, Gay avanzó en la identificación de las formas del relieve características del territorio chileno; además de la obvia representada por las "dos grandes cadenas montañosas o cordilleras", la que llamó "gran valle". Es decir el plano existente entre los Andes y la cordillera de la costa, el hoy llamado valle o llano central que identificó y señaló en sus mapas "prolongándose sin interrupción desde la cuesta de Chacabuco hasta Chiloé, es decir, desde el grado 33 de latitud sur hasta el 42". Advirtiendo, aguda y certeramente, que era "la más importante", la "que da el verdadero carácter al país", la "morada de la civilización chilena, de su comercio y de su industria"33. De ahí también su interés por abordarla en particular, como sus dos tomos sobre la Agricultura chilena lo demuestran.

${ }^{31}$ El texto íntegro de la estrofa del himno patrio chileno que se interpreta es: Puro es, Chile, tu cielo azulado,/ Puras brisas te cruzan también/ i tu campo de flores bordado/ es la copia feliz del Edén./ Majestuosa es la blanca montaña/ que te dio por baluarte el Señor,/ i ese mar que tranquilo te baña/ te promete futuro esplendor".

32 Véase su texto "Cuadro de la vegetación chilena", traducido por Andrés Bello en 1838 por determinación de la Sociedad de Agricultura, en Stuardo Ortiz, 1973, II, pp. 236-244. Más tarde, en 1862, Gay complementó la caracterización de las zonas geográficas y corrigió sus límites. Véase el tomo I de su Agricultura, p. 61.

33 Véanse sus ya citados "Fragmentos de geografía botánica de Chile", p. 321; y su Agricultura, I, pp. 59 y 61. 
Sin embargo, la acción del científico en el territorio no se limitó a la identificación de las unidades básicas del relieve chileno. También tuvo manifestaciones que significaron un cambio evidente en la concepción espacial del nuevo Estado. Por ejemplo, la transformación que experimentó Chiloé a causa de sus representaciones cartográficas.

Si a lo largo del siglo XVIII, y gracias a las preocupaciones defensivas de España, la isla de Chiloé pasó de ignoto a preciada posesión imperial, luego de la independencia su situación cambió radicalmente, incluso hasta perder su condición insular al pasar a formar parte, ahora como posesión remota, del territorio nacional continental.

Para el nuevo Estado, Chiloé no tenía la importancia estratégica que España le había asignado. Por lo pronto, y como hemos advertido que representó Gay, el país se organizó en un eje norte-sur cuyo centro, Santiago y sus zonas adyacentes, tenía como su ámbito de soberanía natural el llano central del territorio continental que, entre cordillera y mar, se desarrollaba entre los desiertos del norte y la zona centro sur que alcanzaba, con esfuerzo, hasta las provincias del sur, justo al norte de Chiloé.

Junto con volver a su condición de aislamiento, de isla en relación al resto de la nación, Chiloé, paradójicamente, en la concepción política de la época, en la representación del territorio del nuevo Estado, dejó de ser isla y pasó a ser parte integrante del continente, del espacio sobre el cual Chile ejercía su soberanía. Su misma precariedad y lejanía hizo olvidar su situación de isla, transformándolo en finis terrae continental del Estado chileno ${ }^{34}$.

En el "Mapa para la inteligencia de la Historia física y política de Chile" Chiloé aparece como parte integrante del continente, como tierra firme, sin que, salvo que se esté advertido, pueda percibirse su condición insular.

En la carta nombrada "Provincia de Chiloé" que preparó Gay, la condición isleña de Chiloé puede, a primera vista, parecer más evidente. Pero lo cierto es que no es así, por el contrario, en la misma aparece también parte del territorio continental, llenando a lo menos el $60 \%$ de la representación, debido a que la provincia de Chiloé, en una nueva demostración de nuestro planteamiento, está compuesta por toda una sección del territorio centro sur de Chile, independiente de si éste es isla o tierra firme.

Así, y por una determinación política, Chiloé y lo asociado a su nombre dejo de tener una connotación exclusivamente isleña. En rigor se materia-

\footnotetext{
${ }^{34}$ No por nada Darwin, que la visitó en 1834 , se refirió a la isla como "ese retirado rincón del mundo", y a Castro, la antigua capital de Chiloé, como a una "ciudad hoy triste y desierta". Véase Darwin, 1998, pp. 258-260.
} 
lizó a nivel legal una situación que ya operaba a nivel de noción de lo que era, o debía ser, Chile nacional: el estrecho espacio entre cordillera y mar situado en la vertiente sur occidental de América del Sur que, por su magnitud y orientación norte sur, prácticamente hacía desaparecer los accidentes que, como las isla de Chiloé, no formaban parte de ese eje longitudinal.

De este modo, si en el contexto colonial, cuando la gobernación de Chile era y se representaba como una sucesión de espacios horizontales que se presentaban ocasionalmente extendiéndose de litoral a cordillera a orillas del mar del Sur, sólo integrados entre sus partes oriental y occidental, pero desconectados unos de otros, Chiloé fue una isla, el verdadero comienzo de Chile y bastión defensivo del imperio español; luego de la independencia, con el paso de colonia a república y el predominio de los intereses nacionales, será el territorio continental de Chile el espacio esencial de la nueva nación, el centro, no sólo de la vida económica, social, política y cultural, también de la construcción espacial de la nueva república y, por todo ello, de la noción geográfica de lo chileno que se materializará en representaciones cartográficas en las que Chiloé apenas se aprecia, y menos como isla.

Contribuyó también a la transformación de Chiloé el método científico utilizado por Gay para levantar sus cartas que, como es sabido, consistió en recoger los datos por medio de la brújula, observando de distancia en distancia algunas latitudes para sus coordenadas. Éste ofreció un grado de exactitud desconocido hasta entonces, de manera que al calcular la distancia exacta de la isla grande de Chiloé respecto de la tierra firme continental, contribuyó a "acercarla", pues las separan sólo 2,6 kilómetros. De este modo, si bien Chiloé estaba cada vez más cerca de Chile, en la misma medida que se le consideraba territorio nacional se alejó cada vez más del centro del nuevo país, transformándose en el territorio más meridional del nuevo Estado, un verdadero finis terrae de la república.

Pero no sólo eso. A raíz de los estudios del científico, Chiloé disminuyó en tamaño y, por lo tanto, y prácticamente como una metáfora de lo que ocurrió a nivel de su presencia en la conciencia nacional, también decayó en importancia para el Estado republicano. Situación que se vio reflejada en el mapa de Chile luego de que el naturalista descubriera en 1836 que "se da a la isla grande de Chiloé una magnitud de dos grados, cuando en realidad se extiende sólo un grado y treinta y cuatro y media millas, lo que produce un error de 26 millas y la hace cerca de 9 leguas mayor de lo que es en realidad"35.

\footnotetext{
35 Informe de Claudio Gay sobre su viaje científico y estudios realizados en las provincias de Valdivia y Chiloé, aparecido en El Araucano del 8 de julio de 1836.
}

Estudios Geográficos, Vol. LXX, 266, pp. 231-267, enero-junio 2009 ISSN: 0014-1496, eISSN: 1988-8546, doi: 10.3989/estgeogr.0454 
El naturalista advirtió así algo que era evidente, y no sólo por un error de método o técnica para calcular la superficie y posición de un territorio determinado. Chiloé estaba sobredimensionada en términos de extensión e insularidad, entre otras razones, porque para el imperio español cumplía un papel determinante en su política defensiva en el Pacífico o Mar del Sur. Tal vez, y siempre desde el punto de vista defensivo, la isla de era más apreciada que todo el resto de la gobernación de Chile. Como se comprenderá, esta realidad no podía sino cambiar luego de 1810, cuando el Estado, a través de trabajos como los de Claudio Gay, comenzó a conocer, organizar y administrar el territorio bajo su soberanía.

Con sus trabajos y representaciones cartográficas, el científico contribuyó a configurar el espacio de la nueva república, pero también a asentar la noción de territorio nacional. En este proceso, incluso lo dilató, como la inclusión en sus mapas de la zona de los archipiélagos australes lo demuestra. En el camino, al privilegiar lo nacional sobre lo local, terminó transformando la geografía al, como el caso de Chiloé lo ejemplifica, diluir en el conjunto nacional los espacios regionales coloniales.

El uso de la cartografía para la creación de Chile como nación no fue un acto inconsciente en Gay. Además de todo lo expuesto, ya en 1831 advertía sobre el valor del reconocimiento geográfico para tal efecto cuando explicó que "deseando un hacer un trabajo absolutamente nacional, he considerado "dedicar a los beneméritos de la patria todos los volcanes, islas, etc., que tenga ocasión de visitar en mis excursiones" 36 .

Los cambios de textos introducidos en su obra respecto de la extensión de Chile y la localización de sus zonas geográficas es otra manifestación de la tarea nacional emprendida por Gay. En efecto, si en sus trabajos de la década de 1830, cuando sólo había explorado entre Aconcagua y Chiloé, no ofrece información sobre la superficie y límites exactos del país; en 1862, después de haber recorrido las provincias del extremo norte y recogido la información de otros científicos que estudiaban y reconocían el país, decidió ampliar y modificar sus noticias y conclusiones sobre la geografía nacional.

En 1862, en la Agricultura que forma parte de su Geografía física y política, Gay ofrece un capítulo que titula "De los terrenos y de su superficie", en el cual escribe que "Chile forma en la extremidad sud-oeste de la América meridional una larga franja de tierra que se extiende desde el $23^{\circ}$ de latitud hasta el

36 "Viaje científico. Segundo informe sobre sus exploraciones en la provincia de Colchagua". Stuardo Ortiz, 1973, II, p. 101. 
$56^{\circ}$, es decir hasta el cabo de Hornos, confín sur del Nuevo Mundo" 37 . De este modo, entre su llegada al país en 1828, y su prácticamente último texto sobre Chile, el país había extendido su límite norte desde el paralelo 27, que aproximadamente muestra en su mapa de 1836 publicado en 1854, hasta el paralelo 23, al norte de la península de Mejillones. También había consolidado su soberanía sobre las "Tierras Magallánicas" situadas al sur de la llamada isla grande de Chiloé.

Atento a las polémicas sobre el límite norte del país, que en 1842 Chile había determinado en el paralelo $23^{\circ}$ y Bolivia establecido en el $25^{\circ}$, el científico incluye como superficie chilena la que el Estado nacional reivindicaba, hecho que adquiere todavía más significación si se considera que los dos tomos de la Agricultura eran fruto de una iniciativa personal del sabio ajena a su compromiso con el gobierno.

Habiendo dilatado su extensión, no debe extrañar que Gay redefiniera los límites de las zonas geográficas identificadas en 1838. En 1862 la norte, que también nombra región del desierto, comprende, precisamente, el vasto desierto de Atacama. La que llama "región centro" ahora se extendía "desde Copiapó hasta la extremidad de la isla de Chiloé; y la sur comprendía desde los $43^{\circ}$, o límite meridional de Chiloé, hasta el cabo de Hornos. Sin embargo, al momento de abordar las características específicas de cada una de ellas, vuelve a su planteamiento original y escribe que la "zona norte se extiende desde Copiapó hasta el cordón de Chacabuco", es decir desde el límite meridional del desierto de Atacama, y el borde septentrional de la cuenca de Santiago en el centro del país ${ }^{38}$. Muestra inequívoca de, a lo menos, dos hechos. Primero, que Gay sólo aborda la descripción de las zonas efectivamente exploradas por él; segundo, que su obra también sufre los efectos de la incertidumbre existente entonces respecto del real límite norte del país.

La inclusión en su Atlas de los planos de las bahías y los puertos de Chile fue otro de sus aciertos. Gay cartografía los más importantes de entonces, como Valparaíso y Constitución, tanto por su valor estratégico, como por el tráfico que se realizaba a través de ellos. También incluye un plano de Santiago con el detalle de su traza, reconociendo así el papel preeminente que, desde su fundación, había tenido la ciudad para la sociedad chilena. Por último, la inclusión en su obra del plano de la batalla de Maipú, que en 1818 ha-

37 Véase texto citado, tomo I, p. 49.

${ }^{38}$ La región central estaba comprendida entre Chacabuco y el río Biobío; la sur se extendía desde el Bíobío al cabo de Hornos. Es decir, Gay volvía totalmente a sus planteamientos originales sobre el tema. 
bía sellado la independencia nacional, ejemplifica que tras la elección de las representaciones existió una meditada decisión destinada a destacar los hitos constitutivos de la nación. Ejemplo a su vez del imaginario sobre el país presente en los chilenos de aquel período fundacional.

Esta conclusión también se puede aplicar al resto de sus composiciones. Apreciando el valor de las estampas, incluyó en su Atlas cuarenta y seis láminas que permiten apreciar el estado de una población particular, la belleza de un paisaje natural o la representación de un hecho significativo para la historia, como por ejemplo un parlamento en la Araucanía o el incendio de Valparaíso. Todas ellas son preciosos testimonios del quehacer de culturas originales, como las que muestran restos arqueológicos, o bien de espacios urbanos o hábitat naturales. Pero también de costumbres, modos de ser, hábitos, faenas y tareas campesinas y mineras, medios de transporte, vestidos, diversiones y tipos sociales ya desaparecidos. En general, sus láminas de ciudades, costumbres y paisajes, reflejan no sólo su paso por diferentes regiones del país, en especial, que Gay supo distinguir las principales actividades, preocupaciones, hitos históricos, usos, características, fiestas y elementos distintivos del país que recorrió, estudio, describió, representó y delineó.

Si la realidad geográfica, económica, social y cultural del Chile que pasa de colonia a república está registrada en el Atlas, las representaciones del mundo natural y de las especies que entonces lo habitaban también se ofrecen en toda su magnitud, integrando así el mundo natural a los componentes de la nueva nación. Ciento tres estampas de diversos vegetales, y ciento treinta y cinco de animales ofrecen un ilustrativo registro de la flora y fauna del territorio nacional $^{39}$. Entre ellas el huemul y el cóndor, especies a las que Gay dedica en su texto particular atención, pues formaban parte del escudo de armas de la república desde 1834.

La cartografía preparada por Claudio Gay fue valorada en su época, en especial porque hasta el momento de su publicación no existía otra a la que acudir, en especial para los espacios interiores. Entonces, primeras décadas del siglo XIX, el "Mapa de Chile" de Nicolás Lobato y Cuenca, que comprendía el territorio entre los $21^{\circ} 30^{\prime}$ de latitud sur hasta los $47^{\circ} \mathrm{S}$, era el que más cabalmente representaba el país, a pesar de ser una representación colonial. En lo que respecta a la hidrografía, las cartas de Parker King y Robert Fitz-Roy, publicadas por la Hidrograffical Office de Londres, representaban la cartografía

39 En este sentido, y sin duda por influencia de Humboldt, el Atlas ofrece un magnífico ejemplo de la estrecha dependencia entre arte y ciencia. 
más completa, base de todos los trabajos que se llevaron a cabo a lo largo del siglo $\mathrm{XIX}^{40}$.

El propio Gay en numerosas ocasiones se refirió a su cartografía, en especial al método seguido para prepararla y al valor que ella podía tener. En 1853, aludiendo al total de su trabajo, escribió que lo había realizado tal y como la ciencia de su época y las necesidades del país lo exigían; previniendo, eso sí, que "sin duda, en ella se encontrarán errores y omisiones". Dando como ejemplo su cartografía, agregó que sus cartas "ofrecerán a veces posiciones no completamente exactas, pero cuando uno piensa que la posición de Valparaíso varía según los autores, a pesar de que tantos sabios astrónomos se han ocupado de ella, se haría mal un mal servicio tratar de criticar algunos errores que, en definitiva, no pueden tener ninguna consecuencia para el uso de una carta geográfica"41.

A pesar de sus deficiencias, que por lo demás jamás pretendió ocultar, su cartografía fue valorada pues, como señalo uno de sus evaluadores, "antes del viaje del señor Gay no se conocía sobre el interior de Chile nada más que el mapa de Tomás López, publicado por Molina en 1785"42. Según Diego Barros Arana el sabio trabajó en sus mapas con paciencia infinita, hecho que resultó en una faena satisfactoria. Para el insigne historiador, "los mapas de Gay, bastante buenos como conjunto de indicaciones geográficas, merecen ser calificados de excelentes cuando se considera el estado en que se hallaban los conocimientos de la geografía de nuestro territorio"43.

El mismo Gay concibió sus cartas como un primer intento de levantar una cartografía nacional. Consciente que "por más que mis mapas hubieran sido de la mayor exactitud, no habría impedido al gobierno hacerlos recomenzar cuando las necesidades administrativas lo hubieran exigido", recordaba que sus mapas "fueron emprendidas al principio con todo el cuidado de que era capaz"; pero que en vistas de que ese trabajo lo distraía de sus investigaciones principales, "creí debí contentarme con hacer mis levantamientos con la brújula, observando a distancia latitudes para mis coordenadas". Considerando que para el científico una carta geográfica del país "no tiene otro objeto que el de dar a conocer la posición de las ciudades, aldeas, ríos, etc., desde un punto

\footnotetext{
40 Medina, 1889, pp. CXIV-CXV.

${ }^{41}$ Carta a Manuel Montt, fechada el 14 de noviembre de 1853, Feliz Cruz y Stuardo Ortiz, 1962, p. 125.

42 "Informe sobre la obra de don Claudio Gay intitulada Historia física y política de Chile, presentado a la Academia de Ciencias de París, por los señores Boussingault y Milne Edwards", Stuardo Ortiz, 1973, II, p. 386.

43 Barros Arana, 1911, p. 407.
} 
de vista relativo", las inexactitudes de la suya no tenían mayor importancia en vistas del objetivo esencial ${ }^{44}$.

Para el Estado chileno la labor cartográfica del naturalista representó una obra de primera necesidad. En su mensaje anual ante el Congreso Nacional de 1835, el mandatario José Joaquín Prieto aludió al asunto señalando que "un mapa exacto del territorio de la república debe ser uno de los principales objetos de sus recomendable trabajos"45. Años después, y habiendo entregado Gay al gobierno sus primeras representaciones del territorio, en diciembre de 1841, se ordenó "la publicación en grande escala del mapa de la república que levantó, y un atlas que comprenda un mapa particular de cada provincia" 46 .

Entre los hombres del gobierno la publicación de la obra de Gay representó para Chile la "posesión de preciosos documentos", entre ellos "la edición del mapa general de la república" 47 . El valor del mismo se apreciará mejor si se considera que desde su elaboración en borrador en 1836, y su publicación en 1854, fue utilizado por quienes, como Vicente Pérez Rosales, compusieron textos sobre la realidad natural y política del país. Éste, por ejemplo, en su Ensayo sobre Chile, una obra de divulgación publicada originalmente en francés en Europa en 1856 con el objeto de dar a conocer el país y atraer inmigrantes, decidió incluir un mapa general de Chile elaborado sobre la base del trazado por Gay, "el cual nos hemos permitido reproducir en proporciones más reducidas y con las principales modificaciones que la ciencia y los nuevos descubrimientos han hecho necesarias" 48 .

Hasta la aparición de la Geografía física de la república de Chile de Amadeo Pissis en 1875, que incluyó un atlas del país levantado luego de una completa medición geodésica del territorio comprendido entre Copiapó y el río Biobío, la cartografía de Chile de Gay fue la usada por el Estado y sus agentes como por los particulares, a pesar de las omisiones y errores que contenía ${ }^{49}$. Para nuestro estudio, más trascendente que la ubicación exacta de las coordenadas 130.

${ }^{44}$ Carta a Manuel Montt de 26 de junio de 1856. Feliz Cruz y Stuardo Ortiz, 1962, pp. 129-

45 Chile, 1899, p. 110.

46 "Memoria del Ministro de justicia, culto e instrucción pública" presentada al Congreso en 1842. Montt, 1905, II, pp. 89 y 90.

${ }_{47}$ Montt, 1095, p. 131.

48 Pérez Rosales, 1986, p. 43. El texto de Pérez Rosales fue publicado en castellano, en Santiago, el mismo año de su edición francesa.

49 Al igual que el trabajo cartográfico de Claudio Gay, el de Pissis también fue apreciado, advirtiéndose sí que "un trabajo de esta naturaleza ni queda desde luego completo, ni puede tampoco dejar de adolecer de errores de alguna consideración”. Medina, 1889., p. CXXVI. 
o la confiabilidad de los accidentes del terreno representados, en definitiva, más que la llamada "verdad topográfica"; importa la imagen de Chile que el mapa de Gay contribuyó a fijar en la conciencia nacional. La cual, por lo demás, no sólo guió la acción del Estado entonces, además, ha permanecido vigente como elemento de esencial de la nacionalidad. Evidencia determinante a la hora de evaluar su obra como primer geógrafo de la república.

La cartografía del sabio francés no sólo se encuentra ligada indisolublemente al surgimiento del Estado-nación chileno, en tanto lo identifica, determina sus fronteras y caracteriza su topografía esencial; además, fue fruto de una iniciativa pública dirigida, precisamente, a dotar al Estado de los instrumentos necesarios para consolidarse, ejercer sus atribuciones soberanas y propender a la formación de la nación.

Los mapas del Atlas de la Historia física y política de Chile, junto con representar la realidad, se anticipa a ella, transformándose en modelo de lo que debía contener el territorio del Estado republicano. A través de ellos se consolidan dominios, pero también se refuerzan pretensiones y se imaginan espacios nacionales por el sólo hecho de incluirlos en la cartografía chilena ${ }^{50}$.

Siguiendo a Anderson, el "Mapa de Chile" de Claudio Gay se convirtió en verdadero logotipo del Estado-nación ${ }^{51}$. Al ser reconocido y transformarse en distintivo propio de Chile, penetro profundamente en la mentalidad colectiva, y no sólo a nivel nacional. Evolucionó en emblema de la nación, en fuente y guía de su acción hacia el futuro; pero también en hito demarcador del territorio y de la acción de la sociedad que lo habitaba.

Claudio Gay da origen a la geografía chilena, en el sentido de definir el espacio nacional y diferenciarlo de otros por sus fronteras, sustrayéndolo así de la visión geográfica continental, regional, amplia, que, al modo de Humboldt, había caracterizado el estudio de los naturalistas hasta comienzos del siglo XIX. Sin considerar que las unidades geográficas y las unidades espaciales se traslapan y tienen áreas de contacto muy fluidas, Gay, como muchos otros en su época, configura nítidamente un país, respondiendo así a las exigencias de la "geografía nacional".

Pero con su obra el naturalista geógrafo marcó también el espacio donde se desenvolvería la "historia de Chile". Al fijar los contornos de Chile, delimitó

50 El incremento de la cartografía gubernamental a lo largo del siglo xIx es un hecho acreditado. Incluso se habla de "que la búsqueda de una prioridad geográfica se convirtió en una competición nacional". Thrower, 2000.

51 Véase Benedict Anderson, Comunidades imaginadas. Reflexiones sobre el origen y la difusión del nacionalismo, Argentina, Fondo de Cultura Económica, 2000. 
no sólo la frontera material del Estado republicano, también el ámbito geográfico que debía tomar en cuenta la historia nacional; favoreciendo de paso el carácter centralista y capitalino de la historiografía nacional al haber identificado el llano central, y a Santiago, como el ámbito característico de la sociedad chilena. Así, no debe sorprender que el científico historiador, compelido a escribir la historia política de Chile, la circunscribiera esencialmente a los sucesos del pasado acontecidos en la zona central.

De este modo, la historia de Chile, como la de muchos otros estados nación en América, es fruto de su materialización como espacio, como territorio, como unidad geográfica identificable y, por tanto, necesitada de un pasado que legitimara y dotara de contenido histórico a la naturaleza cartografiada que le sirve de guía.

Recibido: 10/03/2009

Aceptado: 23/03/2009

\section{BiBLIOGRAFÍA}

Anderson, B. (2000): Comunidades imaginadas. Reflexiones sobre el origen y la difusión del nacionalismo, Fondo de Cultura Económica, Argentina.

Annino, A, y Guerra, F.-X. (2003): Inventando la nación. Iberoamérica. Siglo xix, Fondo de Cultura Económica, México.

Barros Arana, D., Don Claudio Gay, su vida y obras, en Obras completas de..., tomo XI, Imprenta Cervantes.

Chile, El pasado republicano de Chile. O sea colección de discursos pronunciados por los Presidentes de la República ante el Congreso Nacional al inaugurar cada año el período legislativo. 1832-1900, tomo I, Imprenta de "El País", Concepción, 1899.

Codazzi, A., Resumen de la geografía de Venezuela, Imprenta de H. Fournier y Cía, París, 1841.

Darwin, Charles R. (1998): Viaje de un naturalista alrededor del mundo, Miraguano Ediciones, Madrid.

Feliz Cruz, G. y Stuardo Ortiz, C. (1962): Correspondencia de Claudio Gay, Ediciones de la Biblioteca Nacional, Santiago, p. 2.

Gay, C. (2004): Atlas de la historia física y política de Chile, LOM Ediciones y Centro de Investigaciones Diego Barros Arana, Santiago.

Gay, C., Historia física y política de Chile, en casa del autor y Museo de Historia Natural de Santiago, París y Chile, 1844-1871.

Harley, J. B. (2005): La nueva naturaleza de los mapas. Ensayos sobre la historia de la cartografía, Fondo de Cultura Económica, México. 
Medina, J. T., Ensayo acerca de una mapoteca chilena, o sea de una colección de los títulos de los mapas, planos y vistas relativos a Chile arreglados cronológicamente, Imprenta Ercilla, Santiago, 1889.

Montt, L., Discursos, papeles de gobierno i correspondencia de don Manuel Montt, Imprenta Cervantes, Santiago, 1905.

Pérez Rosales, V. (1986): Ensayo sobre Chile, Ediciones de la Universidad de Chile, Santiago.

Sagredo Baeza, R. (2004): "Claudio Gay y la obsesión por representar Chile”, en redición del Atlas de la historia física y política de Chile, Centro de Investigaciones Diego Barros Arana y LOM Ediciones, Santiago.

González Leiva, J. I. (2004): La Expedición Malaspina en la frontera austral del imperio español, Santiago, Editorial Universitaria y Centro de Investigaciones Diego Barros Arana.

Stuardo Ortiz, C. (1973): Vida de Claudio Gay. Escritos y documentos, Editorial Nascimento y Fondo Histórico y Bibliográfico José Toribio Medina, Santiago.

Thrower, Norman J. W. (2000): Mapas y civilización. Historia de la cartografía en su contexto cultural y social, Ediciones del Serbal, España.

\section{RESUMEN}

El trabajo aborda la obra cartográfica del naturalista de origen francés Claudio Gay quién, contrado por el gobierno chileno en 1830 para explorar, reconocer y estudiar el territorio chileno y sus recursos, terminó preparando la primera cartografía de carácter nacional del país. El quehacer geográfico de Gay es apreciado en el contexto de las relaciones entre ciencia y poder, y sus mapas interpretados como un instrumento esencial de la administración estatal en cuanto herramienta para la integración territorial y el ejercicio de la soberanía.

PAlabras Clave: Chile siglo XIX; ciencia; cartografía; Estado; representación territorial; soberanía nacional.

\section{ABSTRACT}

This work considers the cartographic work that French naturalist Claudio Gay completed after he was hired by the Chilean government in 1830 to explore, recognize and study Chile's territory and its resources. All of these made the first national cartography of the country possible. Claudio Gay's cartographic contribution is valued in the context of the relationships between science and power and his maps are interpreted both as essential instruments for state administration and as tools for territorial integration and sovereignty purposes.

KEY WORDS: Chile Nineteenth Century; Science; Cartography; State; Territorial Representation; National Sovereignty 


\section{RÉSUMÉ}

Cette étude porte sur l'œuvre cartographique du naturaliste d'origine française Claudio Gay qui, engagé par le gouvernement chilien en 1830 pour explorer, examiner et étudier le territoire chilien et ses ressources, finit par préparer la première cartographie à caractère national du pays. L'œuvre géographique de Gay est bien appréciée dans le cadre des relations entre science et pouvoir et ses cartes sont interprétées comme un instrument essentiel de l'administration de l'État en tant qu'outil précieux pour l'intégration territoriale et l'exercice de la souveraineté.

Mots CLÉS: Chili XIX siècle; science; cartographie; État; représentation territoriale; souveraineté nationale. 


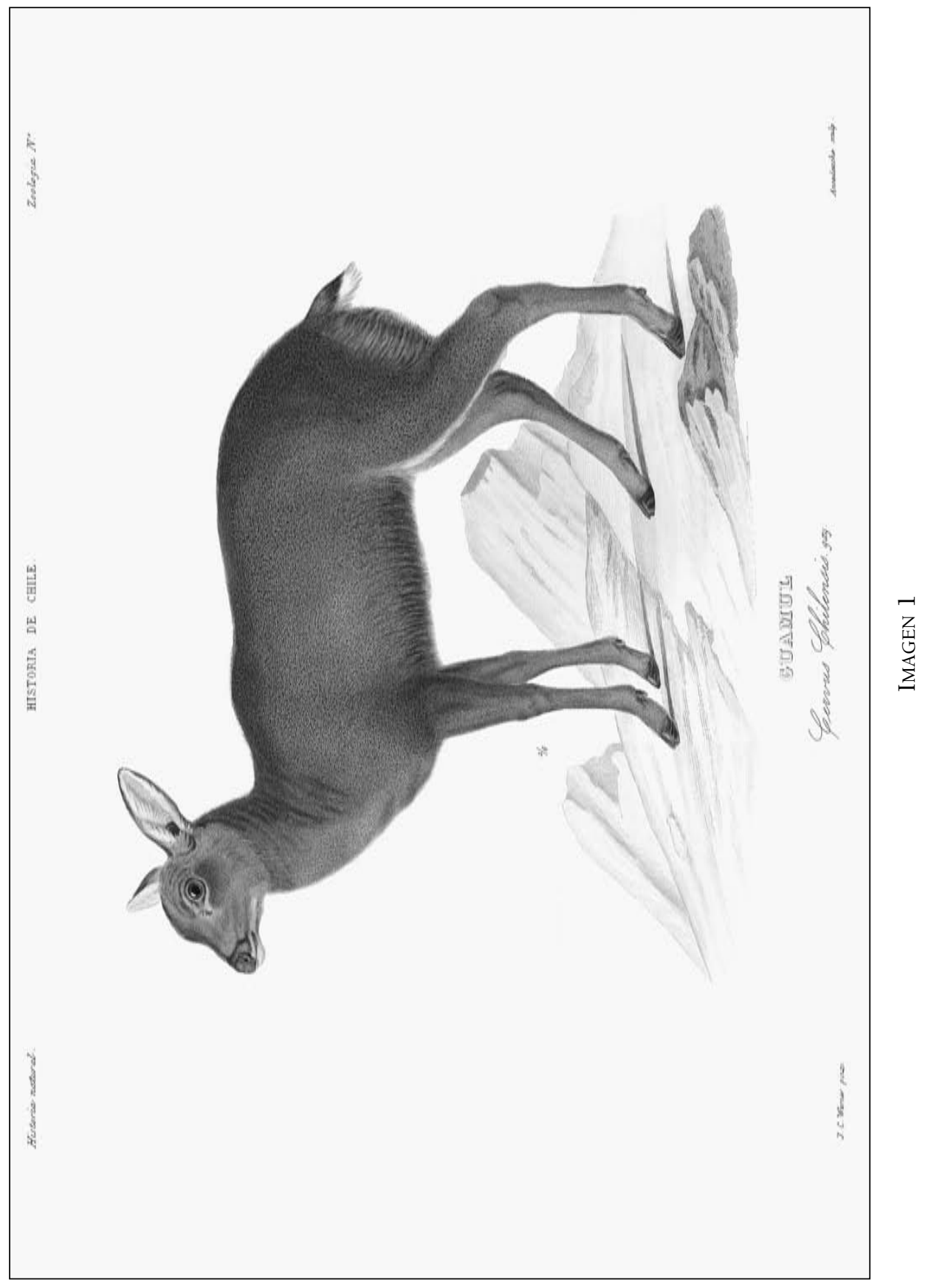

Estudios Geográficos, Vol. LXX, 266, pp. 231-267, enero-junio 2009

ISSN: 0014-1496, eISSN: 1988-8546, doi: 10.3989/estgeogr.0454 


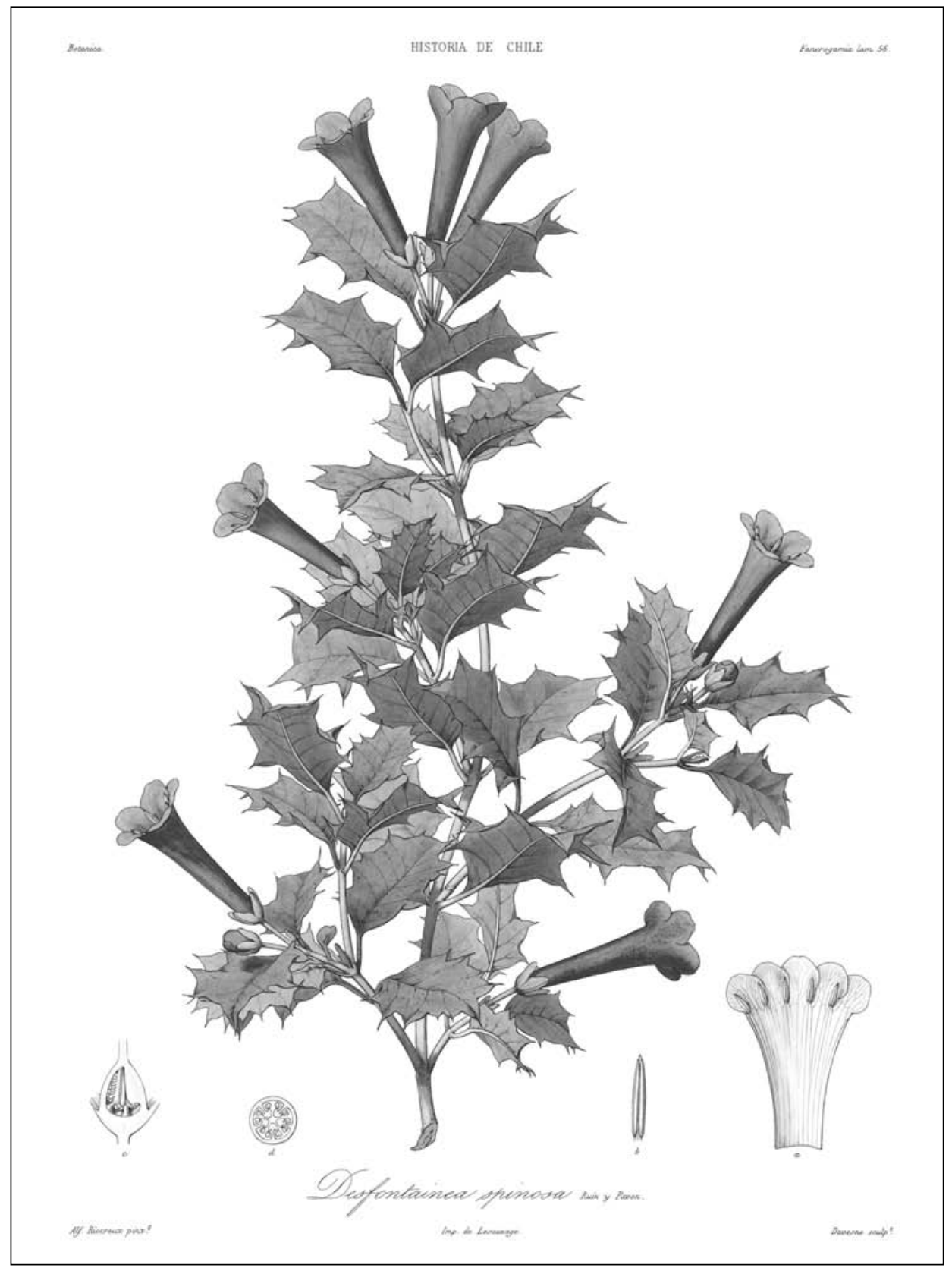

IMAGEN 2

Estudios Geográficos, Vol. LXX, 266, pp. 231-267, enero-junio 2009 ISSN: 0014-1496, eISSN: 1988-8546, doi: 10.3989/estgeogr.0454 


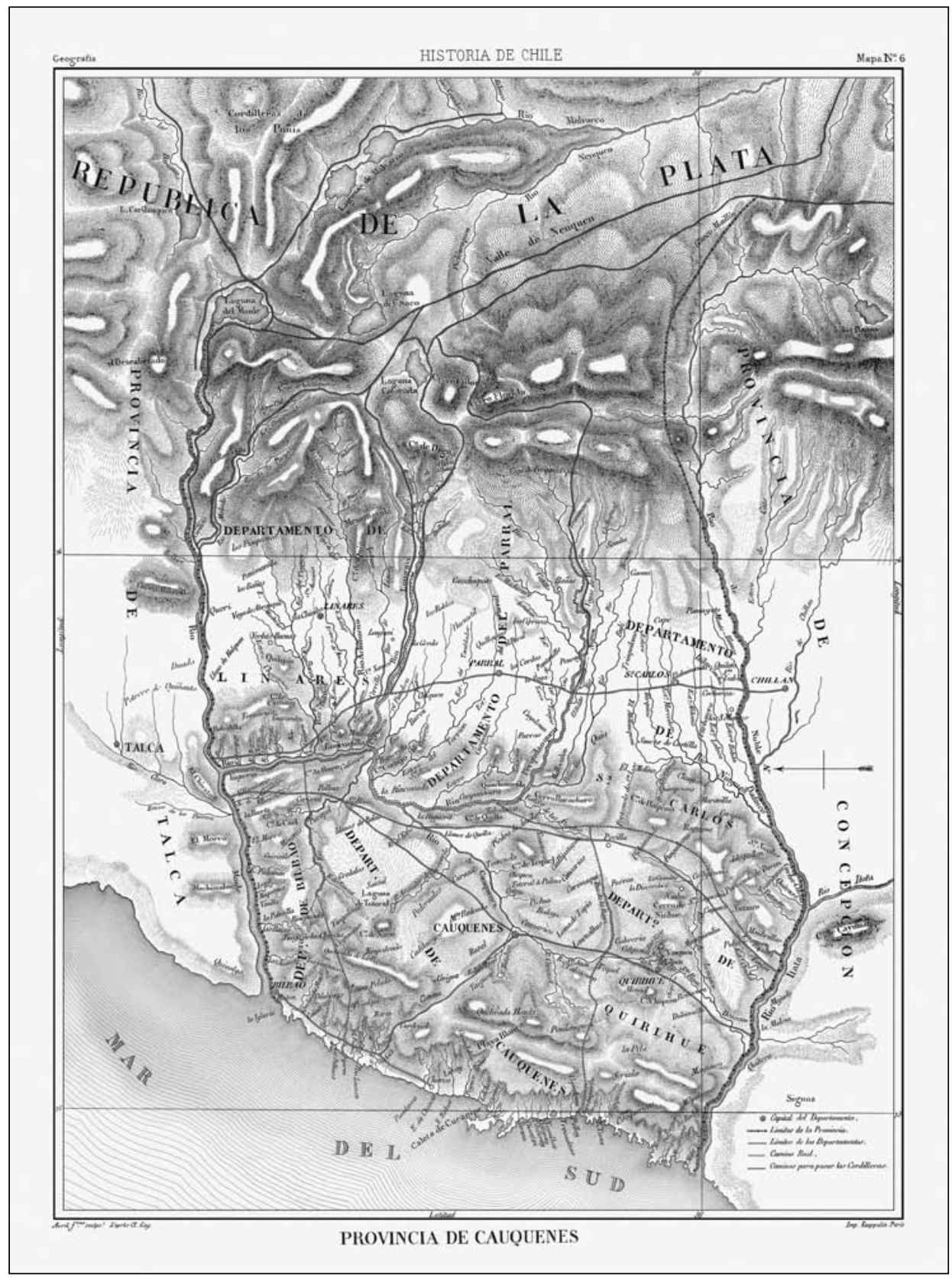

IMAGEN 3

Estudios Geográficos, Vol. LXX, 266, pp. 231-267, enero-junio 2009

ISSN: 0014-1496, eISSN: 1988-8546, doi: 10.3989/estgeogr.0454 


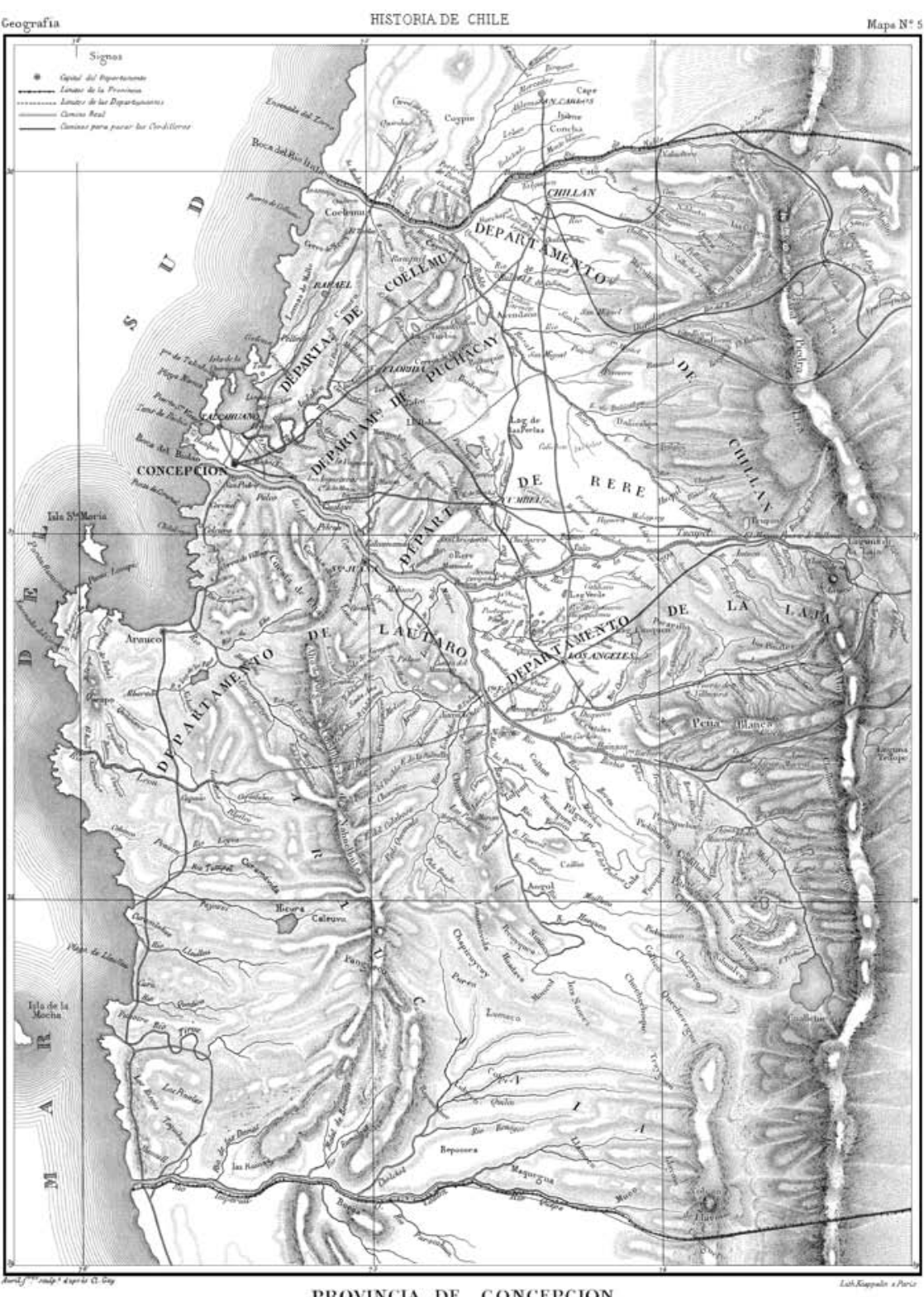

PROVINCIA DE CONCEPCION

IMAGEN 4

Estudios Geográficos, Vol. LXX, 266, pp. 231-267, enero-junio 2009 ISSN: 0014-1496, eISSN: 1988-8546, doi: 10.3989/estgeogr.0454 


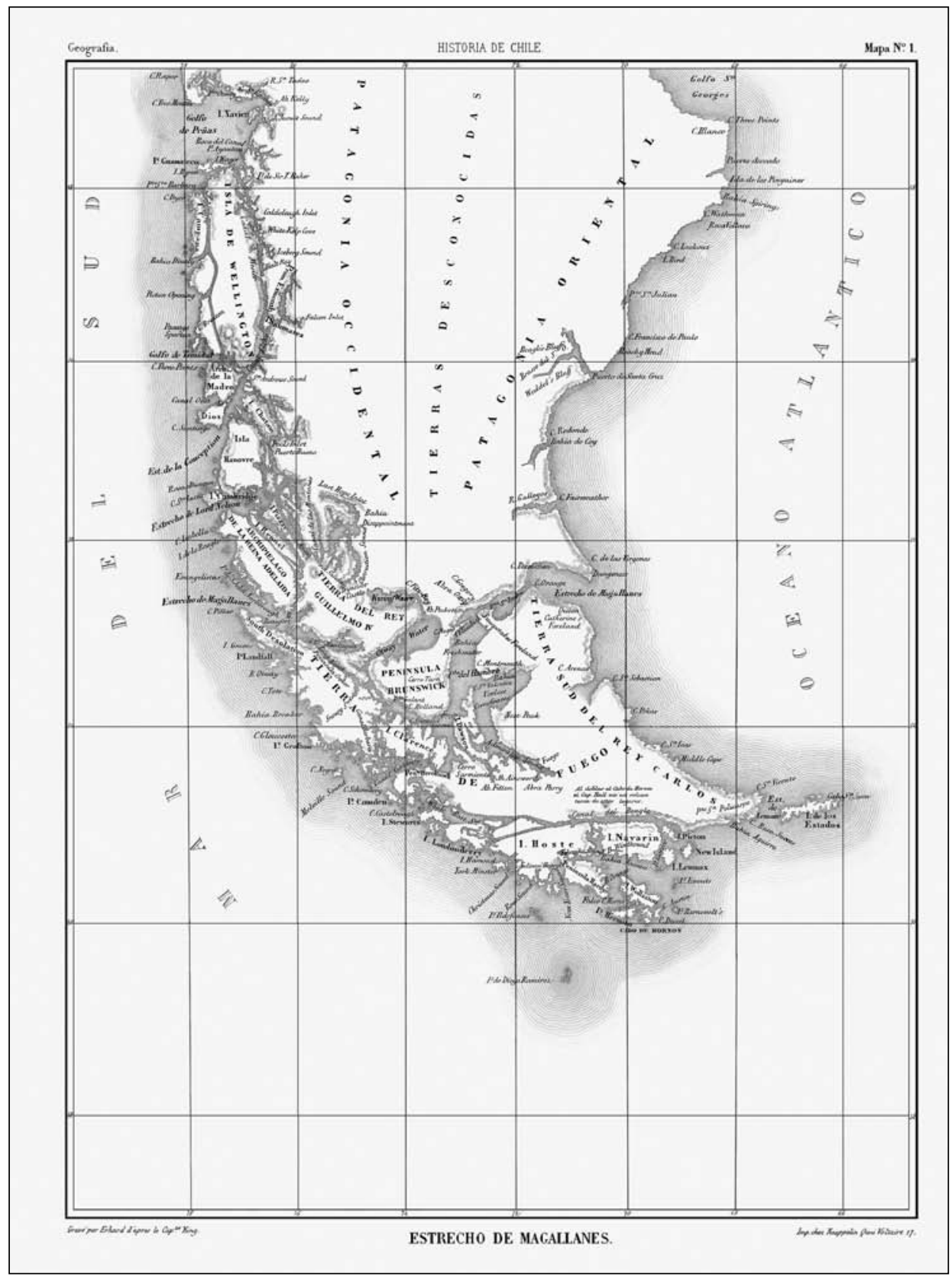

IMAGEN 5

Estudios Geográficos, Vol. LXX, 266, pp. 231-267, enero-junio 2009

ISSN: 0014-1496, eISSN: 1988-8546, doi: 10.3989/estgeogr.0454 


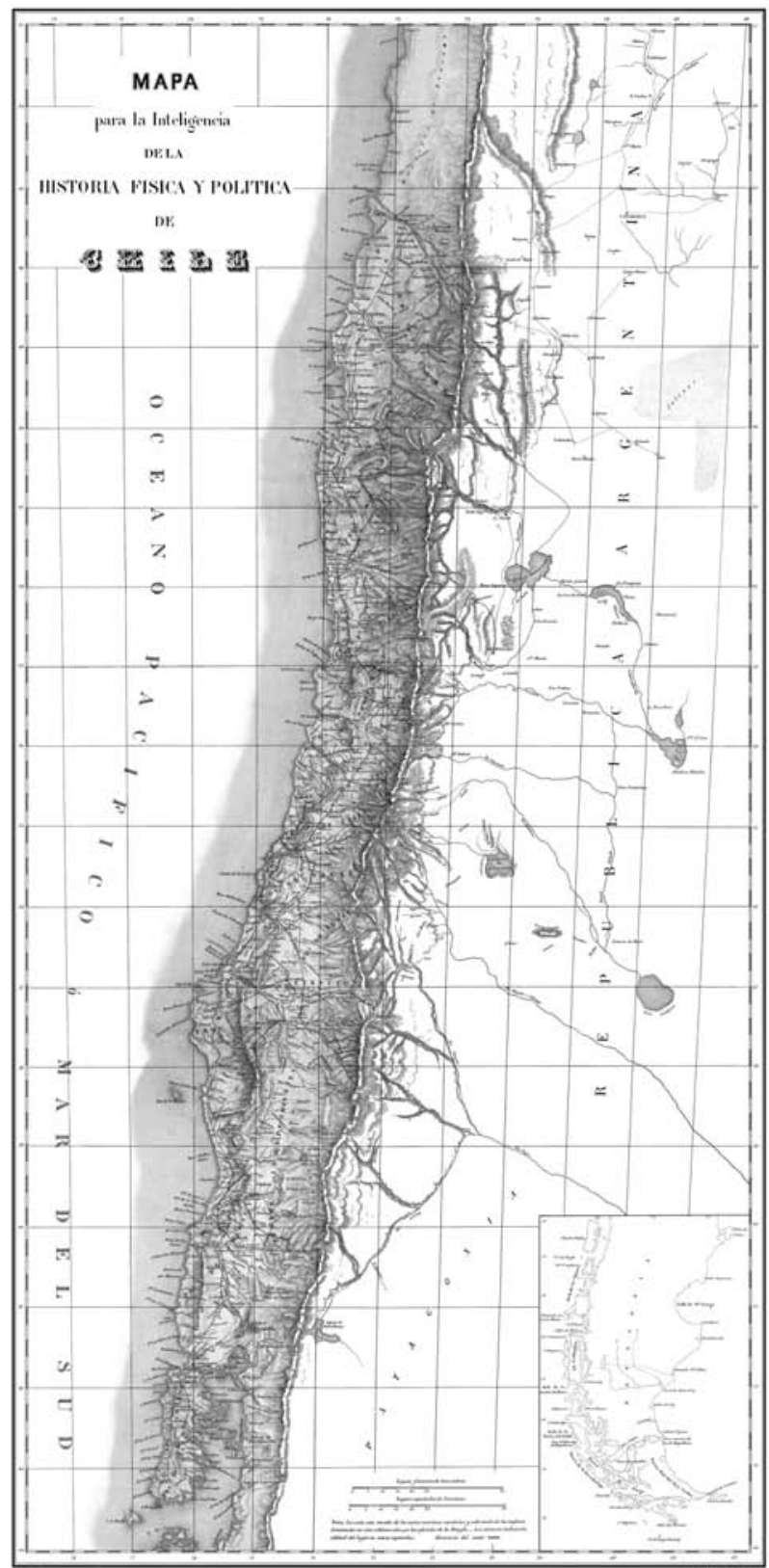

IMAGEN 6

Estudios Geográficos, Vol. LXX, 266, pp. 231-267, enero-junio 2009 ISSN: 0014-1496, eISSN: 1988-8546, doi: 10.3989/estgeogr.0454 


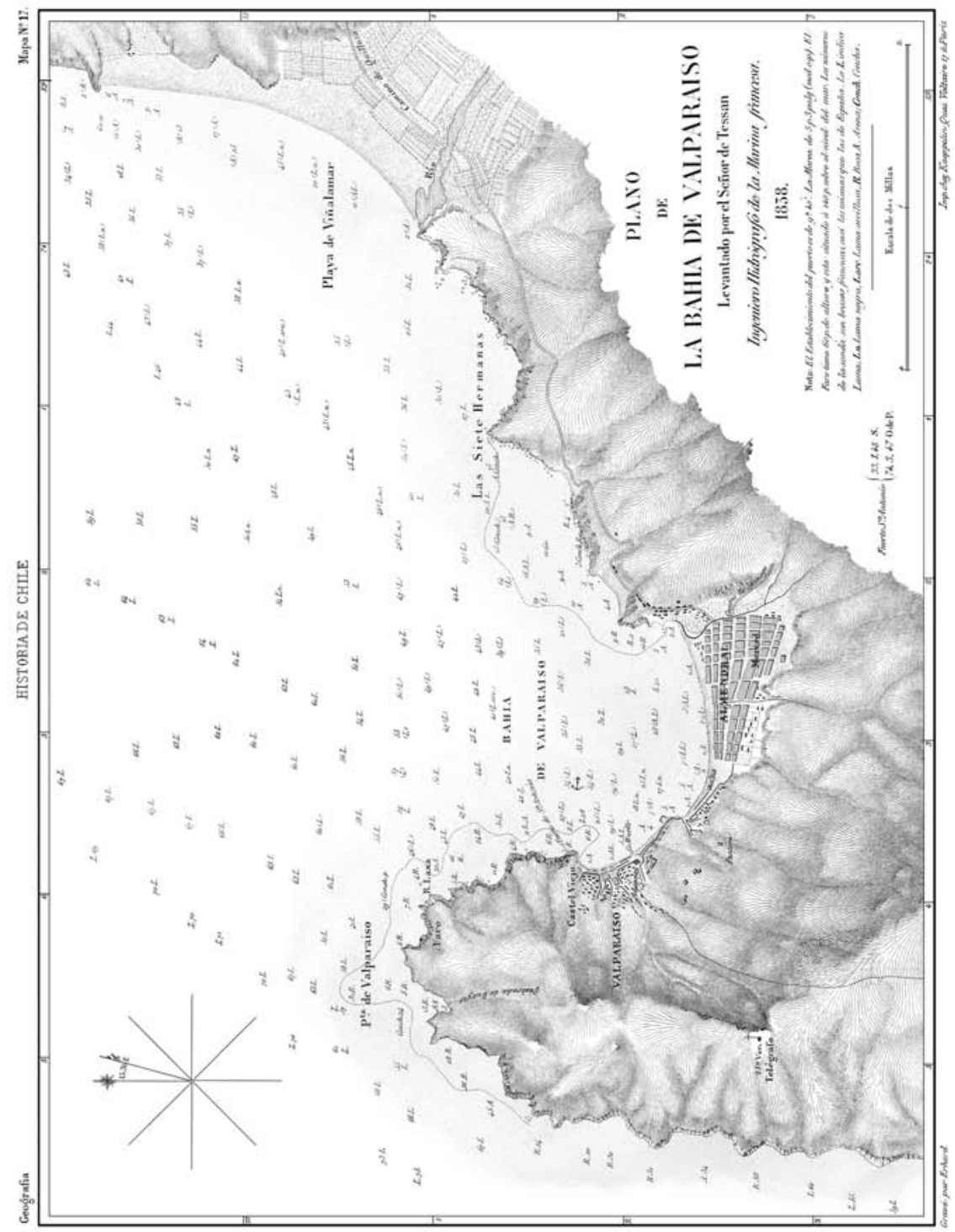

Estudios Geográficos, Vol. LXX, 266, pp. 231-267, enero-junio 2009

ISSN: 0014-1496, eISSN: 1988-8546, doi: 10.3989/estgeogr.0454 


\section{ATLAS}

DE

\section{LA HISTORIA FISICA Y POLITICA}

DE CHILE

POR

\section{CLAUDIO GAY}

T0M0 PRIMER0

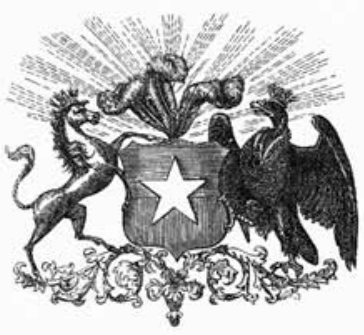

PARIS

EN LA IMPRENTA DE E. THUNOT Y C*

CAlle Racine, 26. CERCA DEL ODEOM

MDCcCLIV

IMAGEN 8

Estudios Geográficos, Vol. LXX, 266, pp. 231-267, enero-junio 2009 ISSN: 0014-1496, eISSN: 1988-8546, doi: 10.3989/estgeogr.0454 